\title{
SAR Studies and Biological Characterization of a Chromen-4-one 2 Derivative as an Anti-Trypanosoma brucei Agent
}

\author{
${ }_{3}$ Chiara Borsari, ${ }^{\ddagger} \dagger$ No Nuno Santarem, ${ }^{\S}$ Sara Macedo, ${ }^{\S}$ María Dolores Jiménez-Antón, " Juan J. Torrado," \\ 4 Ana Isabel Olías-Molero," María J. Corral," Annalisa Tait, \\ ${ }_{s}$ Rosaria Luciani, ${ }^{\ddagger}$ Glauco Ponterini, ${ }^{\ddagger}$ Sheraz Gul, ${ }^{\perp}$ Maria Kuzikov, ${ }^{\perp}$ Bernhard Ellinger, ${ }^{\perp}$ Birte Behrens, ${ }^{\perp}$ \\ ${ }_{6}$ Jeanette Reinshagen, ${ }^{\perp}$ José María Alunda, ${ }^{\|}$Anabela Cordeiro-da-Silva, ${ }^{\S, \#}$ and Maria Paola Costi ${ }^{*}, \odot$ \\ ${ }_{7}^{\ddagger}$ University of Modena and Reggio Emilia, Via Campi 103, 41125 Modena, Italy \\ ${ }_{8}^{\S}$ IBMC and Instituto de Investigação e Inovação em Saúde, Universidade do Porto, 4150-180 Porto, Portugal \\ 9 "Complutense University of Madrid, 28040 Madrid, Spain \\ $10{ }^{\perp}$ Fraunhofer Institute for Molecular Biology and Applied Ecology Screening Port, 22525 Hamburg, Germany \\ 11 \# Departamento de Ciências Biológicas, Faculdade de Farmácia, Universidade do Porto, 4050-313 Porto, Portugal
}

13 ABSTRACT: Chemical modulation of the flavonol 2-(benzo-

14 [d][1,3]dioxol-5-yl)-chromen-4-one (1), a promising anti-

15 Trypanosomatid agent previously identified, was evaluated

16 through a phenotypic screening approach. Herein, we have

17 performed structure-activity relationship studies around hit

18 compound 1 . The pivaloyl derivative (13) showed significant

19 anti-T. brucei activity $\left(\mathrm{EC}_{50}=1.1 \mu \mathrm{M}\right)$ together with a

20 selectivity index higher than 92. The early in vitro ADME-tox properties (cytotoxicity, mitochondrial toxicity, cytochrome P450 and $h$ ERG inhibition) were determined for compound 1 and its derivatives, and these led to the identification of some liabilities. The 1,3-benzodioxole moiety in the presented

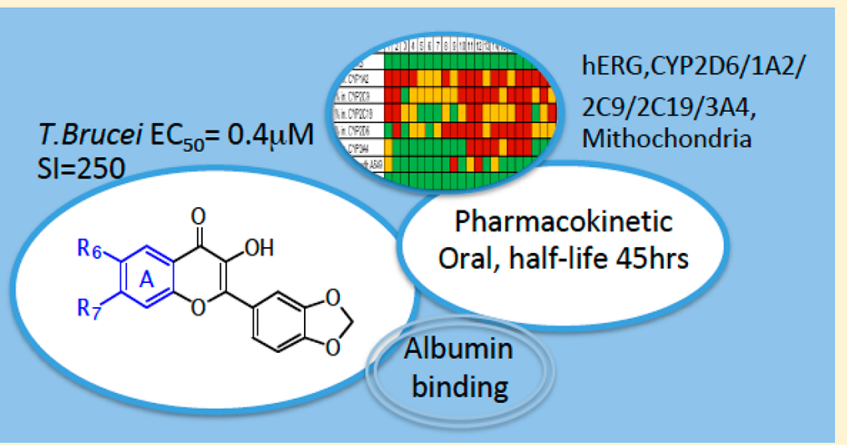
compounds confers better in vivo pharmacokinetic properties

than those of classical flavonols. Further studies using different delivery systems could lead to an increase of compound blood levels.

28 KEYWORDS: Trypanosoma brucei, flavonol-like compounds, SAR studies, ADME-tox properties, neglected tropical diseases

${ }_{20}^{30} \mathrm{~N}$ eglected tropical diseases (NTDs) are a group of infections that affect more than 1.4 billion people 31 worldwide and mainly thrive among the poorest populations in 32 tropical and subtropical areas. ${ }^{1}$ Kinetoplastid parasites are 33 responsible for the potentially fatal insect-borne diseases, 34 namely Chagas disease, Human African Trypanosomiasis 35 (HAT), and Leishmaniasis. ${ }^{2}$ HAT, also known as sleeping 36 sickness, is caused by infection with the gambiense and 37 rhodesiense subspecies of the extracellular protozoan parasite 38 Trypanosoma brucei (T. brucei). ${ }^{3}$ The tsetse fly, Glossina spp., is 39 the vector of the sleeping sickness disease. ${ }^{4}$ According to the 40 World Health Organization (WHO), HAT continues to be a 41 public health issue with an estimated number of new cases per 42 year around 20000 and an estimated population at risk of 65 43 million people. ${ }^{5}$ Despite the serious health, economic, and 44 social consequences of $T$. brucei infections, effective vaccines 45 are lacking and the limited existing drug therapy presents 46 drawbacks including toxicity, poor efficacy, and serious side 47 effects. Most of the available drugs have been used for over half 48 a century; thus, problems of drug resistance are emerging.
Therefore, there is an urgent need for new, safe and effective 49 drugs. $^{6}$ A phenotypic approach is a useful tool for drug 50 discovery with the advantage of identifying compounds which 51 are active against the whole cell. Membrane permeability, cell 52 uptake, and cell efflux are taken into account in the selection of 53 new hits through phenotypic screening. ${ }^{7}$ Phenotypic ap- 54 proaches to drug discovery have been successfully used in 55 the field of neglected diseases, particularly for the treatment of 56 HAT. 8 ,9 Two compounds discovered through phenotypic 57 screening have recently been progressed into clinical trials by 58 DNDi (Drugs for Neglected Diseases initiative): fexinidazole, a 59 nitroimidazole and SCYX-7158, an oxaborole. ${ }^{10}$ A wide range 60 of chemical structures, including flavonols (3-hydroxy-2- 61 phenylchromen-4-one), have been investigated in drug 62

Special Issue: Highlighting Medicinal Chemistry in Italy

Received: November 21, 2018

Accepted: January 29, 2019

Published: January 29, 2019 
63 discovery programs with the aim of identifying novel 64 antileishmanial and antitrypanosomatid agents. ${ }^{11-15}$ Very 65 recently, we had replaced the phenyl ring of classical flavonols 66 with heteroaromatic rings and biphenyl rings and we had 67 synthesized a series of flavonol-like compounds with improved 68 antiparasitic activity with respect to classical flavonols (Figure 69 1). Compound 1 bearing a 1,3-benzodioxole was identified as

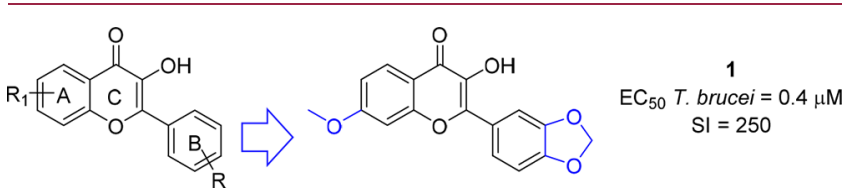

Figure 1. SAR studies on flavonol-like compounds and identification of compound 1 .

70 the most active and selective molecule toward T. brucei $\left(\mathrm{EC}_{50}\right.$ $71=0.4 \mu \mathrm{M}$, Selectivity Index $(\mathrm{SI})=250)($ Figure 1$)$. $^{16}$ 72 According to the biological activity profile, compound 1 was 73 suitable for progression in the drug discovery path. Moreover, 74 the 1,3-benzodioxole represents a crucial pharmacophore with 75 diverse biological activities and has been exploited in bioactive 76 compounds with a wide range of medical applications, 77 including cancer, ${ }^{17,18}$ tuberculosis, ${ }^{19}$ hepatitis $\mathrm{B},{ }^{20}$ fungal 78 infections, $^{21}$ and parasitic diseases. ${ }^{22,23}$

79 The aims of our study were to validate compound 1 through 80 structure activity relationship (SAR) studies, discover follow81 up hits, and characterize their biological profile for potential 82 liabilities identifications. The synthetic procedure followed for 83 the synthesis of the compounds $(\mathbf{1 - 2 1})$ is shown in Scheme 1, 84 and the chemical structures are depicted in Tables $1-3$. The 85 chalcones (22-34) were synthesized by Claisen-Schmidt 86 condensation using substituted acetophenones and benzalde87 hydes in the presence of $\mathrm{NaOH}$ as base. The reaction was carried out in ethanol as previously reported. ${ }^{15}$ The chalcones 88 were converted into the corresponding flavonol-like com- 89 pounds (1-10, 19-21) using the Flynn-Algar-Oyamada 90 method for epoxidation and subsequent intramolecular 91 cyclization of the open-chain structure (Scheme 1A). For the 92 synthesis of esters (11-15) and carbamate 16, compound 193 was treated with an excess of acyl chloride in dry DCM and in 94 the presence of triethylamine. The reaction was carried out at 95 room temperature overnight. For the synthesis of ethers 1796 and 18, alkyl halide was added to a solution of compound $\mathbf{1}$ in 97 dry DMF and in the presence of $\mathrm{K}_{2} \mathrm{CO}_{3}$. The reaction was 98 carried out under microwave irradiation (Scheme 1B). 99

The novel library of flavonol-like compounds (2-21) was 100 evaluated toward T. brucei bloodstream form. The series was 101 assessed for cytotoxicity on THP1 macrophage-like cells to 102 estimate the $\mathrm{CC}_{50}$. For compounds showing a percentage of 103 parasite growth inhibition higher than 70\%, the dose-response 104 curve (DRC) was performed. The percentages of parasite 105 growth inhibition at $10 \mu \mathrm{M}$ are reported in Table S1 of the 106 Supporting Information.

We started the SAR investigation of this scaffold by 108 modifying the substituents on ring A (Table 1). Nine 109 compounds (2-10) were synthesized introducing different 110 substituents in position 6 and 7 of ring A. Five compounds (2, 111 4, 8-10) showed a significant activity toward T. brucei with 112 $\mathrm{EC}_{50}$ lower than $5 \mu \mathrm{M}$. When the $\mathrm{OCH}_{3}$ in position 7 of 113 compound 1 was replaced with a methyl group and a chlorine 114 or fluorine $(\mathbf{8}, \mathbf{9}$, and $\mathbf{1 0}$, respectively), the compounds 115 maintained a meaningful anti-T. brucei activity. Moving the 116 methoxy group from position 7 to 6 (compound 3), we 117 observed a huge drop of the antiparasitic activity. Compound 118 2, bearing unsubstituted ring A, and compound 4, with a 119 methyl group in position 6 showed activity toward T. brucei, 120 while compounds bearing halogen in position 6 (5-bromide; 6- 121

Scheme 1. (A) Synthesis of the Compounds 1-10 and 19-21. ${ }^{a}$ (B) Synthesis of the Compounds 11-18

A)<smiles>[R]#CC(=O)[Al]CCC</smiles><smiles>[R][R]1ccc2oc([Al])c(O)c(=O)c2c1</smiles>

CHALCONES 22-34

B)

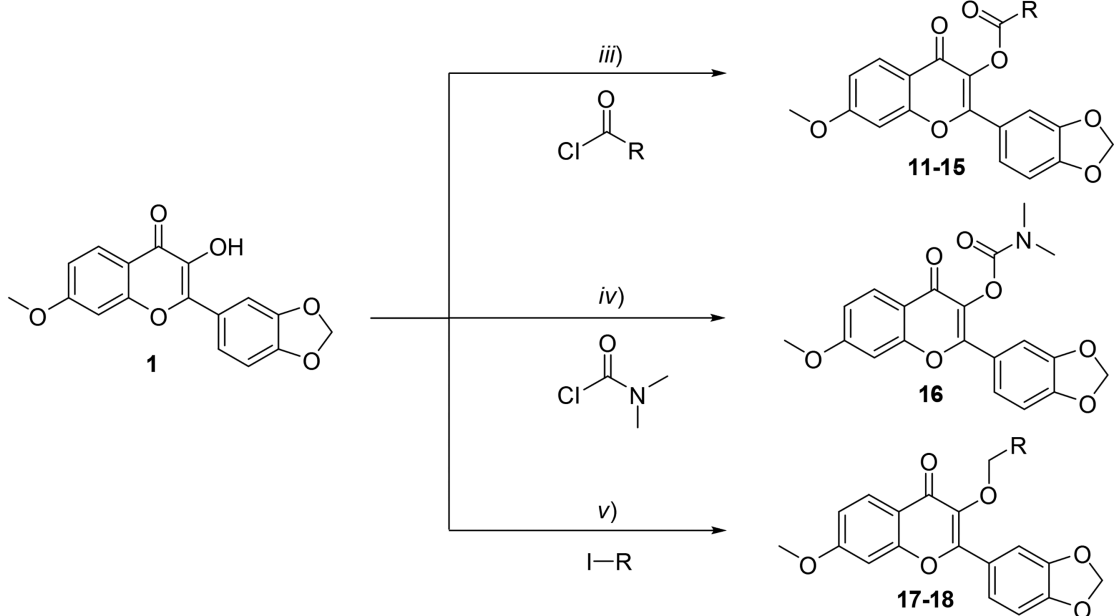

${ }^{a}$ Reaction conditions: (i) $\mathrm{NaOH}(3 \mathrm{M})$, EtOH, r.t.; (ii) $\mathrm{H}_{2} \mathrm{O}_{2}$, $\mathrm{NaOH}(1 \mathrm{M})$, EtOH, r.t. ${ }^{b}$ Reaction conditions: (iii) acyl chloride, dry DCM, $\mathrm{N}_{2}$, r.t.; (iv) carbamoyl chloride, dry DCM, r.t.; (v) alkyl halide, dry DMF, MW $80^{\circ} \mathrm{C}, 0.5 \mathrm{~h}$. 
Table 1. SAR Study on Ring A of the Cromen-4-one Scaffold

\begin{tabular}{|c|c|c|c|c|c|c|}
\hline Comp. & $\mathbf{R}_{3}$ & $\mathbf{R}_{6}$ & $\mathbf{R}_{7}$ & $\mathrm{EC}_{50} \pm \mathrm{SD}(\mu \mathrm{M})$ & $\mathrm{CC}_{50}(\mu \mathrm{M})$ & SI \\
\hline 1 & $\mathrm{OH}$ & $\mathrm{H}$ & $\mathrm{OCH}_{3}$ & $0.4 \pm 0.1$ & $>100$ & 250 \\
\hline 2 & $\mathrm{OH}$ & $\mathrm{H}$ & $\mathrm{H}$ & $2.9 \pm 0.4$ & $12.5<\mathrm{CC}_{50}<25$ & 4 \\
\hline 3 & $\mathrm{OH}$ & $\mathrm{OCH}_{3}$ & $\mathrm{H}$ & & $<12.5$ & \\
\hline 4 & $\mathrm{OH}$ & $\mathrm{CH}_{3}$ & $\mathrm{H}$ & $4.1 \pm 2.1$ & $<12.5$ & $3^{a}$ \\
\hline 5 & $\mathrm{OH}$ & $\mathrm{Br}$ & $\mathrm{H}$ & & $12.5<\mathrm{CC}_{50}<25$ & \\
\hline 6 & $\mathrm{OH}$ & $\mathrm{Cl}$ & $\mathrm{H}$ & & $<12.5$ & \\
\hline 7 & $\mathrm{OH}$ & $\mathrm{F}$ & $\mathrm{H}$ & & $12.5<\mathrm{CC}_{50}<25$ & \\
\hline 8 & $\mathrm{OH}$ & $\mathrm{H}$ & $\mathrm{CH}_{3}$ & $0.4 \pm 0.1$ & $12.5<\mathrm{CC}_{50}<25$ & 31 \\
\hline 9 & $\mathrm{OH}$ & $\mathrm{H}$ & $\mathrm{Cl}$ & $3.8 \pm 4.0$ & $<12.5$ & $3^{a}$ \\
\hline 10 & $\mathrm{OH}$ & $\mathrm{H}$ & $\mathrm{F}$ & $2.4 \pm 0.3$ & $<12.5$ & $8^{a}$ \\
\hline
\end{tabular}

${ }^{a}$ Only estimations as the lower threshold of toxicity were not determined, $\mathrm{EC}_{50}>10 \mu \mathrm{M}$. The reference compound for T. brucei was pentamidine $\left(\mathrm{IC}_{50}=1.55 \pm 0.24 \mathrm{nM}\right)$. The synthesis of compounds $\mathbf{1},{ }^{28} \mathbf{2},{ }^{29} \mathbf{3},{ }^{30} \mathbf{4},{ }^{31} \mathbf{5},{ }^{30} \mathbf{6}^{30} \mathbf{7},{ }^{30} \mathbf{8},{ }^{32}$ and $\mathbf{9}^{33}$ has been already published in the literature. Compound $\mathbf{1 0}$ is a novel structure and has not been previously reported in the literature.

Table 2. SAR Study on the Hydroxyl Group in Position 3 of the Cromen-4-one Scaffold

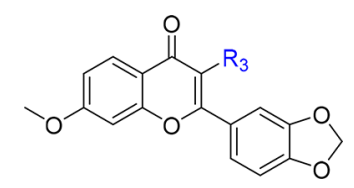

\begin{tabular}{|c|c|c|c|c|}
\hline Comp. & $\mathbf{R}_{3}$ & $\begin{array}{c}\mathrm{EC}_{50} \pm \mathrm{SD} \\
(\mu \mathrm{M})\end{array}$ & $\begin{array}{l}\mathrm{CC}_{50} \\
(\mu \mathrm{M})\end{array}$ & SI \\
\hline 11 & & $0.3 \pm 0.3$ & $<12.5$ & $46^{*}$ \\
\hline 12 & & $0.5 \pm 0.1$ & $<12.5$ & $24^{*}$ \\
\hline 13 & & $1.1 \pm 0.2$ & $>100$ & $>92$ \\
\hline 14 & & $0.6 \pm 0.2$ & $<12.5$ & $22^{*}$ \\
\hline 15 & & $0.5 \pm 0.1$ & $12.5<\mathrm{CC}_{50}<25$ & 25 \\
\hline 16 & & - & $>100$ & - \\
\hline 17 & & - & $50<\mathrm{CC}_{50}<100$ & - \\
\hline 18 & & - & $12.5<\mathrm{CC}_{50}<25$ & - \\
\hline
\end{tabular}

*Only estimations, as the lower threshold of toxicity was not determined, $\mathrm{EC}_{50}>10 \mu \mathrm{M}$. The reference compound for T. brucei was pentamidine $\left(\mathrm{IC}_{50}=1.55 \pm 0.24 \mathrm{nM}\right)$. Compounds 11-18 are novel structures and have not been previously reported in the literature.

122 chlorine; 7-fluorine) did not significantly inhibit T. brucei cells 123 growth. Compound $8\left(\mathrm{EC}_{50}=0.4 \mu \mathrm{M}\right)$ displayed a potency 124 comparable to that of the starting hit $\mathbf{1}$; however, it presented a 125 reduced selectivity index $(\mathrm{SI}=31)$.

126 Following this, our SAR was focused on modifications of the 127 hydroxyl group in position 3 of the chromen-4-one scaffold 128 (Table 2). The presence of an ester instead of a hydroxyl group 129 in position $3(\mathbf{1 1 - 1 5})$ led to significant activity on T. brucei
Table 3. SAR Study Modifying the 1,3-Benzodioxole Ring of Compound $1^{a}$

(

a. $\mathrm{EC}_{50}>10 \mu \mathrm{M}$. The reference compound for $T$. brucei was pentamidine $\left(\mathrm{IC}_{50}=1.55 \pm 0.24 \mathrm{nM}\right)$. Compounds $19-21$ are novel structures and have not been previously reported in the literature.

$\left(\mathrm{EC}_{50}<1.1 \mu \mathrm{M}\right)$ together with a SI $>20$. Among the esters, 130 the 3-pivaloyl derivative of compound 1 (13) showed the most 131 interesting profile with an $\mathrm{EC}_{50}$ toward T. brucei of $1.1 \mu \mathrm{M}$ and 132 SI $>$ 92. On the contrary, the presence of a carbamate (16) or 133 an ether (17 and 18) led to inactivity toward T. brucei. These 134 data suggested that the hydroxyl group in position 3 should be 135 free in order to have a meaningful anti-T. brucei activity. The 136 activity of esters can be related to an easier hydrolysis with 137 respect to ethers and carbamates. We enlarged the SAR study 138 modifying the 1,3-benzodioxole ring of compound 1139 (compounds 19-21, Table 3). Compound 19, with two 140 fluorine atoms instead of two hydrogens linked to the 141 dioxolane ring, was less active than the starting compound 1. 142 The anti- $T$. brucei activity decreased replacing the dioxolane 143 ring of $\mathbf{1}$ with a dioxane (compound 20), while it was 144 maintained in compound 21, bearing a tetrahydrofuran. 145 Compound 21 presented an $\mathrm{EC}_{50}$ toward T. brucei equal to 146 $3.1 \mu \mathrm{M}$, but $\mathrm{SI}=8$. Overall, six compounds $(8,11-15) 147$ showed a low micromolar $\mathrm{EC}_{50}$ and $\mathrm{SI}>20$. Compound 13, 148 the 3-pivaloyl derivative of $\mathbf{1}$, was the most selective among the 149 novel synthesized molecules. 
151 The synthesized library was assessed at $10 \mu \mathrm{M}$ in a panel of 152 early in vitro ADME-tox assays including cytotoxicity (A549 153 cell line), mitochondrial toxicity, cytochrome P450 (CYP1A2, 154 CYP2C9, CYP2C19, CYP2D6, and CYP3A4 isoforms) and $155 h$ ERG inhibition. The data are reported in Figure 2 using a

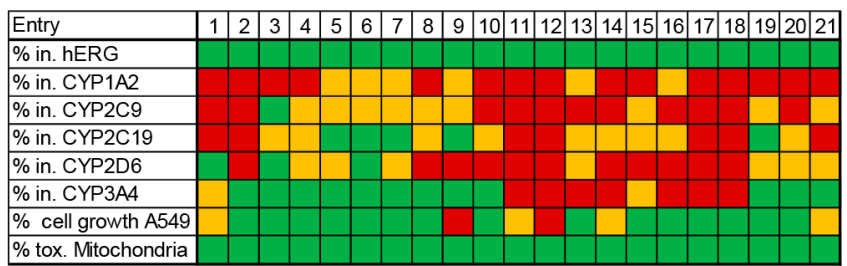

Figure 2. Early in vitro ADME-tox properties of compounds 1-21. All the assays were performed at $10 \mu \mathrm{M}$. The data are reported as a traffic light system. An ideal compound would be expected to be associated with a green color (yielding $<30 \%$ effect). For CYP450, $h E R G$, and mitochondrial toxicity, the cell is colored green when the value is $0-$ $30 \%$, yellow for values $31-60 \%$, and red for values $\geq 61 \%$. Compounds are noncytotoxic (green) when the A549 cell growth value is $60-100 \%$, cytostatic (yellow) for values $0-59 \%$, and cytotoxic (red) for values $<0 \%$.

156 traffic light system. Compound $\mathbf{1}$ and all of its derivatives 157 exhibited no liability toward $h E R G$ and mitochondrial toxicity. 158 Some compounds were shown to be cytostatic, with two 159 compounds ( 9 and 12) being cytotoxic ( $<0 \%$ A549 cell 160 growth). Most of the compounds displayed varying degrees of 161 CYP450 liability. The $\mathrm{IC}_{50}$ toward $h \mathrm{ERG}$ and CYP isoforms 162 were measured for compound 1 . The $h \mathrm{ERG} \mathrm{IC}_{50}(>100 \mu \mathrm{M})$ 163 was over 250 -fold higher than the $\mathrm{EC}_{50}$ toward the parasite, 164 thus in accord with the Target Product Profile (TPP) for hit 165 prioritization. Compound $1 \mathrm{IC}_{50}$ values toward $\mathrm{CYP} 1 \mathrm{~A} 2$ and 166 CYP2D6 were 0.4 and $0.05 \mu \mathrm{M}$, respectively, whereas for 167 CYP2C9, CYP2C19, and CYP3A4 the $\mathrm{IC}_{50}$ values were equal 168 to $1.6,1.5$, and $6.0 \mu \mathrm{M}$, respectively. Compound 1 was the 169 most optimal for its antitrypanosomatid activity and ADME170 tox profile and progressed to in vivo pharmacokinetic studies. 171 In vivo bioavailability and half-life were evaluated in $\mathrm{BALB} / \mathrm{c}$ 172 mice treated IV with $1 \mathrm{mg} / \mathrm{kg}$ and orally with $20 \mathrm{mg} / \mathrm{kg}$. 173 Compound 1 displayed a half-life of $19 \mathrm{~h}$ after iv 174 administration and of $45 \mathrm{~h}$ after oral (os) administration 175 (Table 4). Both AUC and $C_{\max }$ values were similar despite the 176 much higher dose administered per os. $T_{\max }$ for IV 177 administration was reached after $1 \mathrm{~h}$, this suggesting the 178 possible intravascular aggregation of compound $\mathbf{1}$ given its low 179 solubility.

180 The aggregation behavior of compound $\mathbf{1}$ in aqueous 181 solution was investigated spectroscopically and the albumin 182 sequestration assay performed. As compound 1 concentration 183 is increased, both the absorption and the emission spectra 184 show an increase of bands due to aggregates relative to the 185 monomer bands (Figure 3). The absorption data were well 186 fitted in terms of a monomer/dimer equilibrium, with a 1.8 $187( \pm 0.3) \times 10^{5} \mathrm{M}^{-1}$ equilibrium constant at $20{ }^{\circ} \mathrm{C}$ (see the 188 Supporting Information). The fact that the aggregate

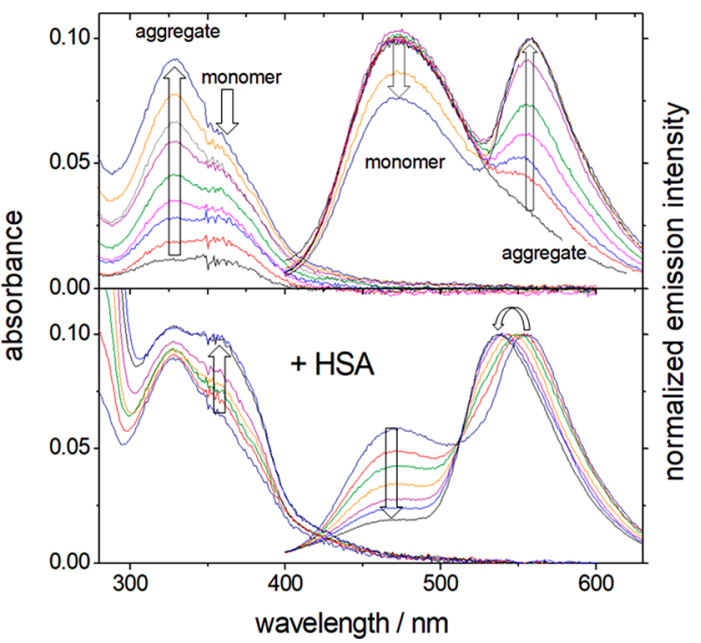

Figure 3. Absorption (left) and fluorescence emission spectra of compound $\mathbf{1}$ in phosphate buffer at $\mathrm{pH} 8$ in the absence (top) and in the presence of human serum albumin (HSA). Top: effect of increasing concentration of compound 1: $1.25,2.5,3.75,5,6.25,7.5$, $8.75,10,11.25 \mu \mathrm{M}$. Bottom: the arrows indicate the effect of the subsequent additions of HSA $(1.68,2.72,4.11,6.65,9.65,13.86 \mu \mathrm{M})$ to the $11.25 \mu \mathrm{M}$ solution of compound 1 . Absorption maxima: free and HSA-complexed monomer, $\approx 360 \mathrm{~nm}$; aggregate, $325 \mathrm{~nm}$. Emission maxima: free monomer, $475 \mathrm{~nm}$; aggregate, $560 \mathrm{~nm}$, HSAcomplexed monomer, $540 \mathrm{~nm}$. $\lambda_{\mathrm{exc}}=320 \mathrm{~nm}$. The emission spectra were normalized to their maximum values for ease of presentation.

absorption band is found at shorter wavelengths and its 189 emission band at longer wavelengths than the corresponding 190 bands of the monomeric form indicates the aggregates to be of 191 H-type (as opposed to a J-type), i.e., with the monomers 192 stacked on top of each other with a small slip angle. ${ }^{24,25} 193$ Subsequent additions of human serum albumin (HSA) caused 194 a progressive recovery of the monomer absorption band and 195 the replacement of both aggregate and free monomer emission 196 bands by a single new band that we assign to a compound 1/ 197 HSA complex. Therefore, the latter represents a stable state 198 with respect to the monomeric and dimeric states. Emission 199 data analysis provided in the Supporting Information allowed 200 us to estimate the 1/HSA binding equilibrium constant, 2.5201 $( \pm 1) \times 10^{5} \mathrm{M}^{-1}$. These results indicate that compound 1 has a 202 tendency to aggregate in aqueous solution that can be reverted 203 by albumin binding. We expect this behavior to occur in blood 204 where albumin binding should help compound solubilization. 205 Chemical changes enhancing solubility are expected to avoid 206 aggregate formation and increase the blood levels of 207 compound 1, thus producing testing.

208

Although removal of systemic infection may be beneficial to 209 host survival, in the second stage HAT (which represents 90\% 210 of the total cases), the parasites colonize the central nervous 211 system. To understand the suitability of compound $\mathbf{1}$ to pass 212 the $\mathrm{BBB}$, we evaluated molecular descriptors, such as 213 lipophilicity (cLogP), molecular weight (MW), and polar 214 surface area (PSA) that provide insight into the factors that 215 govern $\mathrm{BBB}$ penetration. Compound $\mathbf{1}$ fulfills the requirements 216

Table 4. Pharmacokinetic Parameters of Compound 1

$\begin{array}{cccccccc}\text { Comp. } & \text { Dose }(\mathbf{m g}) \text { and route } & \mathbf{C m a x}(\mathbf{n g} / \mathbf{m L}) & \mathbf{C m a x}(\boldsymbol{\mu} \mathbf{M}) & \text { Tmax }(\mathbf{h}) & \text { AUCtot }(\mathbf{n g} / \mathbf{m L} \mathbf{h}) & \text { AUCtot }(\mathbf{n m o l} / \mathbf{m L} \mathbf{h}) & \text { Half life }(\mathbf{h}) \\ \mathbf{1} & 1(\mathrm{IV}) & 340 & 1.08 & 1.00 & 3120 & 9.99 & 19.8 \\ \mathbf{1} & 20 \text { (per os) } & 290 & 0.91 & 0.50 & 2700 & 8.65 & 45.4\end{array}$


217 for BBB penetration, i.e., $\mathrm{CLogP}$ in the range 1.5-2.7 (2.19 for 218 compound 1), MW < 400 (312.3 for compound 1) and PSA < $21990 \AA^{2}$ (74.22 $\AA^{2}$ for compound 1). Additionally, the $10^{5}$ order 220 of magnitude of the 1 /HSA binding equilibrium constant is 221 consistent with that of CNS drugs that do cross the BBB $(6 \times$ $\left.22210^{4} \mathrm{M}^{-1}\right)$. Therefore, we expect compound 1 to be sufficiently 223 lipophilic to be transported by HSA and pass the CNS 224 barrier. $^{26}$

225 In summary, we have validated compound 1 bearing a 1,3226 benzodioxole moiety as a potent anti-Trypanosomatid agent in 227 vitro. ${ }^{16}$ SAR studies around compound 1 have confirmed its 228 profile as a valuable hit to progress to animal studies. We have 229 synthesized 20 derivatives (2-21); compounds 10-21 are 230 novel structures and have not been previously reported. The 231 pivaloyl derivative (13) was the best compound of the hit-to232 lead optimization process. Compound $\mathbf{1 3}$ has significant anti233 T. brucei activity $\left(\mathrm{EC}_{50}=1.1 \mu \mathrm{M}\right)$ together with $\mathrm{SI}>92$ and a 234 reduced toxicity, thus showing a biological profile similar to $\mathbf{1}$. 235 The pharmacokinetic (PK) studies on $\mathbf{1}$ have demonstrated 236 the ability of the 1,3-benzodioxole flavonol derivative to reach 237 plasma concentrations $>\mathrm{EC}_{50}$ for $T$. brucei with oral 238 administration, thus increasing classical flavonols half-life. ${ }^{15}$ 239 Compound $\mathbf{1}$ blood exposure was probably limited due to its 240 low solubility and sequestration by albumin, as shown in 241 aqueous solution experiments. Compound $\mathbf{1}$ is an interesting 242 scaffold for anti-Trypanosomatid drug development that can 243 be further exploited using drug delivery systems such as $\beta$ 244 cyclodextrins which have a proven capacity to improve 245 solubility of flavonoids. ${ }^{27}$

\section{ASSOCIATED CONTENT}

\section{S Supporting Information}

248 The Supporting Information is available free of charge on the 249 ACS Publications website at DOI: 10.1021/acsmedchem250 lett.8b00565.

$251 \quad$ Antiparasitic activity toward Trypanosoma brucei (Table 252 S1); Early ADME-tox data (Table S2); General 253 information and experimental data of synthesized 254 compounds (pp S6-S16) (PDF)

\section{$255 \square$ AUTHOR INFORMATION}

\section{Corresponding Author}

257 *M.P.C.: phone, 0039-059-205-8579; E-mail, mariapaola. 258 costi@unimore.it.

\section{ORCID 요}

260 Chiara Borsari: 0000-0002-4688-8362

261 Stefania Ferrari: 0000-0003-1149-5953

262 Maria Paola Costi: 0000-0002-0443-5402

263 Present Address

${ }_{264}^{\dagger}$ (C.B.) Department of Biomedicine, University of Basel, 265 Mattenstrasse 28, 4058 Basel, Switzerland.

\section{Author Contributions}

267 The manuscript was written through contributions of all 268 authors. All authors have given approval to the final version of 269 the manuscript.

\section{Funding}

271 This project has received funding from the European Union's 272 Seventh Framework Programme for research, technological 273 development, and demonstration under grant agreement no. 274603240 (NMTrypI - New Medicine for Trypanosomatidic 275 Infections).

\section{Notes}

The authors declare no competing financial interest.

\section{ACKNOWLEDGMENTS}

The authors acknowledge the COST Action CM1307, http:// 279 www.cost.eu/COST_Actions/cmst/CM1307 for the contribu- 280 tion to the discussion of the research results.

281

\section{ABBREVIATIONS}

282

ADME-tox, Absorption, Distribution, Metabolism, and Ex- 283 cretion-tox; A549, human lung adenocarcinoma epithelial cell 284 line; $\mathrm{CC}_{50}$, half maximal cytotoxicity concentration; DCM, 285 dichloromethane; DMF, dimethylformamide; DRC, dose- 286 response curve; $\mathrm{EC}_{50}$, half maximal effective concentration; 287 EtOH, ethanol; HAT, Human African trypanosomiasis; $h$ ERG, 288 human ether-a-go-go-related gene; HAS, human serum 289 albumin; $\mathrm{NaOH}$, sodium hydroxide; SI, selectivity index; T. 290 brucei, Trypanosoma brucei; THP1, human monocytic cell line 291

\section{REFERENCES}

292

(1) Soeiro, M. N.; Werbovetz, K.; Boykin, D. W.; Wilson, W. D.; 293 Wang, M. Z.; Hemphill, A. Novel amidines and analogues as 294 promising agents against intracellular parasites: a systematic review. 295 Parasitology 2013, 140 (8), 929-951.

296

(2) Nussbaum, K.; Honek, J.; Cadmus, C. M.; Efferth, T. 297 Trypanosomatid parasites causing neglected diseases. Curr. Med. 298 Chem. 2010, 17 (15), 1594-1617.

(3) Morrison, L. J. Parasite-driven pathogenesis in Trypanosoma 300 brucei infections. Parasite Immunol. 2011, 33 (8), 448-455. 301

(4) Stein, J.; Mogk, S.; Mudogo, C. N.; Sommer, B. P.; Scholze, M.; 302 Meiwes, A.; Huber, M.; Gray, A.; Duszenko, M. Drug development 303 against sleeping sickness: old wine in new bottles? Curr. Med. Chem. 304 2014, 21 (15), 1713-1727.

(5) Squarre, D.; Kabongo, I.; Munyeme, M.; Mumba, C.; Mwasinga, 306 W.; Hachaambwa, L.; Sugimoto, C.; Namangala, B. Human African 307 Trypanosomiasis in the Kafue National Park, Zambi. PLoS Neglected 308 Trop. Dis. 2016, 10 (5), No. e0004567.

(6) Reddy, M.; Gill, S. S.; Kalkar, S. R.; Wu, W.; Anderson, P. J.; 310 Rochon, P. A. Oral drug therapy for multiple neglected tropical 311 diseases: a systematic review. JAMA 2007, 298 (16), 1911-1924. 312

(7) Gilbert, I. H. Drug discovery for neglected diseases: molecular 313 target-based and phenotypic approaches. J. Med. Chem. 2013, 56 (20), 314 $7719-7726$.

315

(8) Sykes, M. L.; Avery, V. M. Approaches to protozoan drug 316 discovery: phenotypic screening. J. Med. Chem. 2013, 56 (20), 7727- 317 7740 .

(9) Borsari, C.; Santarem, N.; Torrado, J.; Olías, A. I.; Corral, M. J.; 319 Baptista, C.; Gul, S.; Wolf, M.; Kuzikov, M.; Ellinger, B.; Witt, G.; 320 Gribbon, P.; Reinshagen, J.; Linciano, P.; Tait, A.; Costantino, L.; 321 Freitas-Junior, L. H.; Moraes, C. B.; Bruno Dos Santos, P.; Alcântara, 322 L. M.; Franco, C. H.; Bertolacini, C. D.; Fontana, V.; Tejera Nevado, 323 P.; Clos, J.; Alunda, J. M.; Cordeiro-da-Silva, A.; Ferrari, S.; Costi, M. 324 P. Methoxylated 2'-'hydroxychalcones as antiparasitic hit compounds. 325 Eur. J. Med. Chem. 2017, 126, 1129-1135.

(10) Eperon, G.; Balasegaram, M.; Potet, J.; Mowbray, C.; Valverde, 327 O.; Chappuis, F. Treatment options for second-stage gambiense 328 human African trypanosomiasis. Expert Rev. Anti-Infect. Ther. 2014, 12329 (11), 1407-1417.

(11) Tasdemir, D.; Kaiser, M.; Brun, R.; Yardley, V.; Schmidt, T. J.; 331 Tosun, F.; Rüedi, P. Antitrypanosomal and antileishmanial activities 332 of flavonoids and their analogues: in vitro, in vivo, structure-activity 333 relationship, and quantitative structure-activity relationship studies. 334 Antimicrob. Agents Chemother. 2006, 50 (4), 1352-1364. 335

(12) Singh, N.; Mishra, B. B.; Bajpai, S.; Singh, R. K.; Tiwari, V. K. 336 Natural product based leads to fight against leishmaniasis. Bioorg. 337 Med. Chem. 2014, 22 (1), 18-45. 
339 (13) da Silva, E. R.; MaquiaveliCdo, C.; Magalhães, P. P. The 340 leishmanicidal flavonols quercetin and quercitrin target Leishmania 341 (Leishmania) amazonensis arginase. Exp. Parasitol. 2012, 130 (3), $342 \quad 183-188$.

343 (14) Arioka, S.; Sakagami, M.; Uematsu, R.; Yamaguchi, H.; 344 Togame, H.; Takemoto, H.; Hinou, H.; Nishimura, S. Potent 345 inhibitor scaffold against Trypanosoma cruzi trans-sialidase. Bioorg. 346 Med. Chem. 2010, 18 (4), 1633-1640.

347 (15) Borsari, C.; Luciani, R.; Pozzi, C.; Pöhner, I.; Henrich, S.; 348 Trande, M.; Cordeiro-da-Silva, A.; Santarém, N.; Baptista, C.; Tait, 349 A.; Di Pisa, F.; DelloIacono, L.; Landi, G.; Gul, S.; Wolf, M.; Kuzikov, 350 M.; Ellinger, B.; Reinshagen, J.; Witt, G.; Gribbon, P.; Kohler, M.; 351 Keminer, O.; Behrens, B.; Costantino, L.; Tejera Nevado, P.; Bifeld, 352 E.; Eick, J.; Clos, J.; Torrado, J.; Jiménez-Antón, M. D.; Corral, M. J.; 353 Alunda, J. M.; Pellati, F.; Wade, R. C.; Ferrari, S.; Mangani, S.; Costi, 354 M. P. Profiling of flavonol derivatives for the development of anti355 trypanosomatidic drugs. J. Med. Chem. 2016, 59 (16), 7598-7616.

356 (16) Ph.D. thesis Borsari, C. Drug discovery and delivery approaches 357 for the identification and optimization of novel agents for neglected 358 tropical diseases and tuberculosis.

359 (17) Wei, P. L.; Tu, S. H.; Lien, H. M.; Chen, L. C.; Chen, C. S.; $360 \mathrm{Wu}$, C. H.; Huang, C. S.; Chang, H. W.; Chang, C. H.; Tseng, H.; Ho, 361 Y. S.J The in vivo antitumor effects on human COLO 205 cancer cells 362 of the 4,7-dimethoxy-5-(2-propen-1-yl)-1,3-benzodioxole (apiole) 363 derivative of 5-substituted 4,7-dimethoxy-5-methyl-1,3-benzodioxole 364 (SY-1) isolated from the fruiting body of Antrodia camphorate. 365 Cancer Res. Ther. 2012, 8 (4), 532-536.

366 (18) Goodarzi, S.; Hadjiakhoondi, A.; Yassa, N.; Khanavi, M.; 367 Tofighi, Z. New Benzodioxole Compounds from the Root Extract of 368 Astrodaucuspersicus. Iran J. Pharm. Res. 2016, 15 (4), 901-906.

369 (19) Deshpande, S. R.; Nagrale, S. N.; Patil, M. V.; Chavan, P. S. 370 Novel 3,4-Methylenedioxybenzene Scaffold Incorporated 1,3,5371 Trisubstituted-2-pyrazolines: Synthesis, Characterization and Evalua372 tion for Chemotherapeutic Activity. Indian J. Pharm. Sci. 2015, 77 (1), 373 24-33.

374 (20) Huber, R.; Hockenjos, B.; Blum, H. E. DDB treatment of 375 patients with chronic hepatitis. Hepatology 2004, 39 (6), 1732-1733. 376 (21) Moon, Y. S.; Choi, W. S.; Park, E. S.; Bae, I. K.; Choi, S. D.; 377 Paek, O.; Kim, S. H.; Chun, H. S.; Lee, S. Antifungal and 378 Antiaflatoxigenic Methylenedioxy-Containing Compounds and Piper379 ine-Like Synthetic Compounds. Toxins 2016, 8 (8), E240.

380 (22) dos Santos Filho, J. M.; Moreira, D. R.; de Simone, C. A.; 381 Ferreira, R. S.; McKerrow, J. H.; Meira, C. S.; Guimarães, E. T.; 382 Soares, M. B. Optimization of anti-Trypanosoma cruzi oxadiazoles 383 leads to identification of compounds with efficacy in infected mice. 384 Bioorg. Med. Chem. 2012, 20 (21), 6423-6433.

385 (23) Mariz Gomes da Silva, L. M.; de Oliveira, J. F.; Silva, W. L.; da 386 Silva, A. L.; de Almeida Junior, A. S. A.; Barbosa Dos Santos, V. H.; 387 Alves, L. C.; Brayner Dos Santos, F. A.; Costa, V. M. A.; Aires, A. L.; 388 de Lima, M. D. C. A. Albuquerque MCPA New 1,3-benzodioxole 389 derivatives: Synthesis, evaluation of in vitro schistosomicidal activity 390 and ultrastructural analysis. Chem.-Biol. Interact. 2018, 283, 20-29.

391 (24) Baraldi, I.; Caselli, M.; Momicchioli, F.; Ponterini, G.; Vanossi, 392 D. Dimerization of green sensitizing cyanines in solution. A 393 spectroscopic and theoretical study of the bonding nature. Chem. 394 Phys. 2002, 275, 149-165.

395 (25) Caselli, M.; Latterini, L.; Ponterini, G. Consequences of H396 dimerization on the photophysics and photochemistry of oxacarbo397 cyanines. Phys. Chem. Chem. Phys. 2004, 6, 3857-3863.

398 (26) Zheng, X.; Li, Z.; Podariu, M. I.; Hage, D. S. Determination of 399 Rate Constants and Equilibrium Constants for Solution-Phase Drug400 Protein Interactions by Ultrafast Affinity Extraction. Anal. Chem. $4012014,86,6454-6460$.

402 (27) Tommasini, S.; Raneri, D.; Ficarra, R.; Calabro, M. L.; 403 Stancanelli, R.; Ficarra, P. Improvement in solubility and dissolution 404 of flavonoids by complexation rate with $\beta$-cyclodextrin. J. Pharm. 405 Biomed. Anal. 2004, 35, 379-387.

406 (28) Williams, A. C.; Camp, N. Product class 4: benzopyranones and 407 benzopyranthiones. Science of Synthesis 2003, 14, 347-638.
(29) Das, S.; Mitra, I.; Batuta, S.; Niharul Alam, M.; Roy, K.; Begum, 408 N. A. Design, synthesis and exploring the quantitative structure- 409 activity relationship of some antioxidant flavonoid analogues. Bioorg. 410 Med. Chem. Lett. 2014, 24 (21), 5050-5054.

(30) Chang-yong, H.; Tae-sik, P.; Young-kwan, K.; Jin-ho, L.; Jong- 412 hyun, K.; Dong-myung, K.; Ho-sun, S.; Sang-woong, K.; Eunice Eun- 413 kyeong, K. Preparation of novel CDK inhibitors having flavone 414 structure. PCT Int. Appl. WO 2000012496 A1 20000309, 2000. 415 (31) Wu, B.; Morrow, J. K.; Singh, R.; Zhang, S.; Hu, M. Three- 416 dimensional quantitative structure-activity relationship studies on 417 UGT1A9-mediated 3-O-glucuronidation of natural flavonols using a 418 pharmacophore-based comparative molecular field analysis model. J. 419 Pharmacol. Exp. Ther. 2011, 336 (2), 403-413.

420

(32) Marathey, M. G.; Naik, V. G.; Gore, K. G. Benzopyrone series. 421 VII. Synthesis of 3',4'-methylenedioxyflavones. Journal of the 422 University of Poona, Science and Technology 1959, 16, 41-49.

(33) Zhang, L.; Fourches, D.; Sedykh, A.; Zhu, H.; Golbraikh, A.; 424 Ekins, S.; Clark, J.; Connelly, M. C.; Sigal, M.; Hodges, D.; 425 Guiguemde, A.; Guy, R. K.; Tropsha, A. Discovery of novel 426 antimalarial compounds enabled by QSAR-based virtual screening. 427 J. Chem. Inf. Model. 2013, 53 (2), 475-492. 